\title{
Influence of adipocyte size and adipose depot on the in vitro lipolytic activity and insulin sensitivity of adipose tissue in dairy cows at the end of the dry period
}

\author{
J. De Koster, ${ }^{+1}$ W. Van den Broeck, $†$ L. Hulpio, ${ }^{*}$ E. Claeys, $¥$ M. Van Eetvelde, ${ }^{*}$ K. Hermans, ${ }^{*}$ M. Hostens, ${ }^{*}$ \\ V. Fievez,‡ and G. Opsomer* \\ *Department of Reproduction, Obstetrics and Herd Health, and \\ †Department of Morphology, Faculty of Veterinary Medicine, Ghent University, Salisburylaan 133, 9820 Merelbeke, Belgium \\ ‡Laboratory for Animal Nutrition and Animal Product Quality, Faculty of Bioscience Engineering, Ghent University, Proefhoevestraat 10 , \\ 9090 Melle, Belgium
}

\section{ABSTRACT}

The aim of the present research was to describe characteristics of adipose tissue lipolysis in dairy cows with a variable body condition score (BCS). Ten clinically healthy Holstein Friesian cows were selected based on BCS and euthanized 10 to $13 \mathrm{~d}$ before the expected parturition date. Immediately after euthanasia, adipose tissue samples were collected from subcutaneous and omental fat depots. In both depots, we observed an increase in adipocyte size with increasing BCS. Using an in vitro explant culture of subcutaneous and omental adipose tissue, we aimed to determine the influence of adipocyte size and localization of adipose depot on the lipolytic activity in basal conditions and after addition of isoproterenol (nonselective $\beta$-agonist) and insulin in different concentrations. Glycerol release in the medium was used as a measure for lipolytic activity. We observed that the basal lipolytic activity of subcutaneous and omental adipose tissue increased with adipocyte volume, meaning that larger fat cells have higher basal lipolytic activity independent of the location of the adipose depot. Dose-response curves were created between the concentration of isoproterenol or insulin and the amount of glycerol released. The shape of the dose-response curves is determined by the concentration of isoproterenol and insulin needed to elicit the half-maximal effect and the maximal amount of stimulated glycerol release or the maximal inhibitory effect of insulin. We observed that larger fat cells released more glycerol upon maximal stimulation with isoproterenol and this was more pronounced in subcutaneous adipose tissue. Additionally, larger fat cells had a higher sensitivity toward lipolytic signals. We observed a trend for larger adipocytes to be more resistant to

Received September 24, 2015

Accepted November 12, 2015

${ }^{1}$ Corresponding author: jenne.dekoster@ugent.be the maximal antilipolytic effect of insulin. The insulin concentration needed to elicit the half-maximal inhibitory effect of insulin was within the physiological range of insulin and was not influenced by adipocyte size or adipose depot. We conclude that overconditioned cows have larger adipocytes and are predisposed to excessive mobilization of body fat due to a higher basal and stimulated lipolytic activity of large adipocytes while the antilipolytic effect of insulin is preserved.

Key words: dairy cow, adipose tissue, in vitro lipolytic activity, in vitro insulin response

\section{INTRODUCTION}

The adipose tissue is an important tissue capable of storing or mobilizing energy during periods of energy excess or deficit, respectively. During the lactation cycle of dairy cows, adipose tissue dynamically transitions from a period of energy storage at the end of lactation through a period of energy mobilization to dampen the negative energy balance at the beginning of lactation (McNamara, 1991). At the end of the dry period and in the beginning of lactation, adipocytes go through a period of pronounced lipolysis, whereas de novo lipogenesis and re-esterification of fatty acids are downregulated (McNamara, 1991; Vernon et al., 2001). Lipolytic pathways in adipocytes are upregulated as part of the homeorhetic adaptation mechanism to preserve sufficient energy for the growing fetus and subsequently the lactating mammary gland. More specifically, adipocytes become insulin resistant, whereas basal and catecholamine-stimulated lipolytic activity are upregulated (Bauman and Currie, 1980; McNamara, 1991; Vernon, 2005).

Excessive mobilization of body fat during late pregnancy and early lactation may lead to elevated nonesterified fatty acid (NEFA) and BHB levels in the blood with a negative effect on health and productivity of dairy cows (Drackley, 1999; Ospina et al., 2013). 
Particularly, overconditioned cows are known to be susceptible to excessive fat mobilization in the periparturient period. This is due to a more pronounced negative energy balance as a consequence of depressed appetite (Drackley, 1999; Grummer et al., 2004). Additionally, it has been hypothesized that the excessive fat mobilization in overconditioned cows may be due to the greater amount of fat available to mobilize, to a more enhanced lipolytic activity or insulin resistance of adipocytes in adipose depots of overconditioned cows, or to a combination of these factors (Rukkwamsuk et al., 1998; Herdt, 2000; Kokkonen et al., 2005).

Furthermore, adipose depots in different regions of the body demonstrate different metabolic activities (Pond, 1992). In humans, ample evidence supports a large heterogeneity in metabolic and endocrine properties between different adipose depots (Wajchenberg, 2000). Sensitivity to catecholamine-stimulated lipolysis is increased, whereas sensitivity to the antilipolytic effect of insulin is reduced in visceral compared with subcutaneous adipocytes (Wajchenberg, 2000). As a consequence, obese individuals mobilize more NEFA from visceral compared with subcutaneous adipose tissue, leading to an overflow of NEFA in the liver with detrimental effects on health (Wajchenberg, 2000). Recent research indicates depot-specific variation in adipose tissue metabolism in dairy cows as well. Hostens et al. (2012) and Drackley et al. (2014) demonstrated different levels of fat mobilization and accumulation between different adipose depots in lactating and nonlactating dairy cows, respectively. Locher et al. (2011, 2012) demonstrated differences in metabolic activation of lipolytic enzymes between adipose depots in dry and lactating dairy cows.

The aim of the present research was to describe characteristics of adipose tissue lipolysis in dairy cows with a variable BCS at the end of the dry period. Using an in vitro explant culture of subcutaneous and omental adipose tissue, we aimed to determine the influence of adipocyte size and localization of adipose depot on the lipolytic activity in basal conditions and, after addition of catecholamines and insulin in different concentrations.

\section{MATERIALS AND METHODS}

All experimental procedures were approved by the ethical committee of the Faculty of Veterinary Medicine (EC2010/149; Ghent University, Belgium).

\section{Study Design}

Ten clinically healthy, pregnant Holstein Friesian dairy cows (upcoming parity 2 to 5 ) were selected at the beginning of the dry period (2 mo before expected parturition date) based on BCS according to the scale of Edmonson et al. (1989). Five animals were considered to have a normal BCS (BCS 2.5 to 3.5), and 5 animals were considered to be overconditioned (BCS 3.75 to 5 ). During the study, animals were fed according to their requirements. The study design is described in detail by De Koster et al. (2015).

Cows were euthanized 10 to $13 \mathrm{~d}$ before the expected parturition date at the Department of Morphology (Faculty of Veterinary Medicine, Ghent University, Belgium). Cows were stunned with a captive bolt gun and exsanguinated by transecting the carotid arteries and jugular veins. Immediately after euthanasia, samples were collected from subcutaneous and omental adipose tissue. Subcutaneous adipose tissue samples were taken from the adipose tissue located in the fossa ischiorectalis, and omental adipose tissue samples were taken from the omentum majus at the right side of the body.

\section{In Vitro Explant Culture}

Immediately after sampling, adipose tissue was minced into small fragments using sharp scissors and transported to the laboratory at $38^{\circ} \mathrm{C}$. Approximately $100 \mathrm{mg}$ of adipose tissue fragments was transferred to a cell culture dish $(35 \times 10 \mathrm{~mm}$, Cellstar, Greiner BioOne, Frickenhausen, Germany) containing $3 \mathrm{~mL}$ of medium. The medium used in this experiment was Krebs Ringer Bicarbonate HEPES buffer (pH 7.4) containing $30 \mathrm{~m} M$ HEPES (H3375, Sigma Aldrich, St. Louis, MO), $5.5 \mathrm{~m} M$ glucose (G6152, Sigma Aldrich), and 3\% fatty acid-free BSA (A6003, Sigma Aldrich). Culture dishes containing explants were incubated on a shaker (gentle agitation) in an incubator at $38^{\circ} \mathrm{C}$. Explants were allowed to accommodate during a 20-min period. After this preincubation, zero-time samples were taken to determine the starting value of glycerol after which hormones were added to the culture dishes. All experimental conditions were performed in duplicate. For assessment of basal lipolysis, no agents were added. Solutions of isoproterenol hydrochloride (ISO, nonselective $\beta$-adrenergic receptor agonist, I6504, Sigma Aldrich) were made fresh on the day of the experiment and added to the cell culture dishes at concentrations of $10^{-6}, 10^{-7}, 10^{-8}$, and $10^{-9} \mathrm{M}$. To determine the inhibitory capacity of insulin on the lipolytic activity of the adipocytes, human insulin (INS; I9278, Sigma Aldrich) at concentrations of $1,10,200$, and $1,000 \mu \mathrm{IU} / \mathrm{mL}$ was added simultaneously with $10^{-6} \mathrm{M}$ ISO to the culture dishes. After $3 \mathrm{~h}$ of incubation, samples of incubation medium were taken for determination of glycerol. Samples for determination of glycerol were stored at $-20^{\circ} \mathrm{C}$ until analysis. 


\section{Glycerol Analysis}

The glycerol concentration in the culture medium was determined using free glycerol reagent (F6428, Sigma Aldrich). Samples, medium (blanco; Krebs Ringer Bicarbonate HEPES Buffer, Sigma-Aldrich), and standards (100 $\mu \mathrm{L}$; Glycerol Standard Solution, G7793, Sigma-Aldrich) were loaded in a 96-well plate, and 300 $\mu \mathrm{L}$ of free glycerol reagent was added. After $10 \mathrm{~min}$ of incubation at room temperature, optical density was measured at $540 \mathrm{~nm}$ and concentration was calculated using a standard curve. Intra- and interassay coefficients of variation were 4.1 and $7.7 \%$, respectively. Glycerol release was determined by subtracting the glycerol concentration in the medium after $3 \mathrm{~h}$ of incubation with the zero-time sample (after $20 \mathrm{~min}$ of preincubation). Results are normalized as glycerol release per million adipocytes using the number of adipocytes per gram of adipose tissue (Viswanadha and Londos, 2008).

\section{Determination of the Number of Adipocytes}

The number of adipocytes per gram of adipose tissue was determined as described by Di Girolamo and Fine (2001). The weight of the explants in each culture dish was precisely determined using an analytical scale (Mettler AE 200, Mettler Toledo, Greifensee, Switzerland). Diameters of the subcutaneous and omental adipocytes were determined after digestion of $1 \mathrm{~g}$ of adipose tissue in $3 \mathrm{~mL}$ of medium containing $2 \mathrm{mg} / \mathrm{mL}$ collagenase (C6885, Sigma Aldrich). Digestion was complete after $1 \mathrm{~h}$ incubation at $38^{\circ} \mathrm{C}$. Samples of the adipocyte suspension were loaded in a culture dish and the diameter of 300 adipocytes was determined using an inverted microscope (Olympus CKX41, Hamburg, Germany). Mean diameter $(\overline{\mathrm{Dia}})$ and standard deviation of the diameter $\left(\mathrm{SD}_{\text {dia }}\right)$ were used to calculate adipocyte volume $\left(\mathrm{V}_{\text {adipocyte }}\right)$ using the Goldrick formula (Goldrick, 1967):

$$
\mathrm{V}_{\text {adipocyte }}=\frac{\pi \times \overline{\mathrm{Dia}} \times\left(3 \times \mathrm{SD}_{\text {dia }}{ }^{2}+\overline{\mathrm{Dia}}^{2}\right)}{6} .
$$

The triglyceride content of the subcutaneous and omental adipose tissue was determined as described previously (Lourenço et al., 2007). Briefly, between 0.5 and $0.8 \mathrm{~g}$ of adipose tissue was extracted overnight with 30 $\mathrm{mL}$ of chloroform:methanol $(2: 1, \mathrm{vol} / \mathrm{vol})$ and $3 \mathrm{~mL}$ of butylated hydroxytoluene in chloroform $(0.1 \%, \mathrm{wt} / \mathrm{vol})$. Samples were then filtered (Fiorini S.A., Fiorini, Ingré, France) and the filtrate was collected. The filter was washed twice with $10 \mathrm{~mL}$ of chloroform:methanol (2:1, $\mathrm{vol} / \mathrm{vol}$ ). The filtrate was transferred to a flat-bottomed flask and evaporated with a rotary vapor (Laborota 4000 WB, Schwabach, Germany) at $40^{\circ} \mathrm{C}$. The dry residue $\left(103^{\circ} \mathrm{C}\right.$ during $\left.2 \mathrm{~h}\right)$ was cooled in a desiccator and the amount of fat was determined gravimetrically. Five-fold replicates were performed for each sample. Lipid density $(\rho)$ was considered to be the density of triglycerides $(0.915 \mathrm{~g} / \mathrm{mL})$. Number of adipocytes per gram of tissue was determined using the following formula (Di Girolamo et al., 1971):

$$
\begin{aligned}
& \text { No. of adipocytes per } \mathrm{g} \text { of adipose tissue } \\
& =\frac{\rho \times \mathrm{V}_{\text {adipocyte }}}{\text { triglyceride content }}
\end{aligned}
$$

\section{Statistical Analysis}

All statistical analyses were performed using SAS version 9.4 (SAS Institute Inc., Cary, NC). Descriptive statistics are expressed as mean \pm standard errors of the mean unless otherwise indicated. Normality of the data and error terms of the models were checked using the Kolmogorov-Smirnov test $(P<0.01)$. Interaction terms were left out the model if not significant $(P>$ 0.05). One overconditioned cow (BCS 4.0) was excluded from final statistical analysis because adipocytes failed to react on ISO. Pearson correlation coefficients were calculated to demonstrate the relationship between BCS and volume of the adipocytes and between number of adipocytes per gram of adipose tissue and volume of the adipocytes. Significance and tendency were declared at $P<0.05$ and $0.05<P<0.1$, respectively.

Basal Glycerol Release. To check for significant effects on basal glycerol release, a model was used with basal glycerol release as dependent variable; whereas depot (subcutaneous and omental) and volume of the adipocytes were included as independent variables. A compound symmetry structure was used to model the duplicate measurements within individual animals. Because basal glycerol release was lognormally distributed, the model was fitted using a generalized linear mixed model (PROC GLIMMIX). Because BCS and volume of the adipocytes were highly correlated ( $\mathrm{r}>$ $0.60)$, only volume of the adipocytes was included as independent variable in the model.

Isoproterenol-Stimulated Glycerol Release. The glycerol release was stimulated using 4 ISO concentrations. Therefore, it was possible to create dose-response curves for the ISO-stimulated glycerol release of the adipose tissue fragments. To correct for differences in 
basal glycerol release between different cows and different depots, the basal glycerol release was subtracted from the ISO-stimulated glycerol release, and thus the incremental glycerol release was modeled. Doseresponse curves were created using the PROC NLIN function using the following equation (Motulsky and Christopoulos, 2004):

$$
\text { Incremental glycerol release }=\frac{\max _{\mathrm{ISO}}}{\left(1+10^{\log \mathrm{ED} 50_{\mathrm{ISO}}-\log \mathrm{ISO}}\right)}
$$

The shape of the dose-response curve was determined by 2 parameters: $\max _{\text {ISo }}$ is the maximal amount of glycerol released from the explants by addition of $10^{-6}$

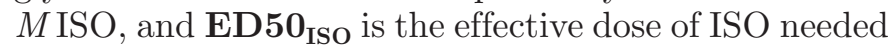
to elicit the half-maximal glycerol release.

Insulin-Inhibited Glycerol Release. The maximal ISO-stimulated glycerol release was inhibited using 4 INS concentrations. Therefore, it was possible to create dose-response curves for the inhibitory effect of insulin on the glycerol release of the adipose tissue explants. To correct for differences in maximal ISO-stimulated glycerol release, the inhibition of the glycerol release is expressed as a percentage of the maximal ISO-stimulated glycerol release without insulin. Dose-response curves were created using the PROC NLIN function using the following equation (Motulsky and Christopoulos, 2004):

$$
\begin{aligned}
& \text { Insulin-inhibited glycerol release }(\%)= \\
& \min _{\mathrm{INS}}+\frac{\left(1-\min _{\mathrm{INS}}\right)}{\left(1+10^{\left.\log \mathrm{INS}-\log E \mathrm{D} 50_{\mathrm{INS}}\right)}\right.} .
\end{aligned}
$$

The shape of the dose-response curve was determined by 2 parameters: $\mathbf{m i n}_{\text {INS }}$ is the minimal percentage of glycerol released from the explants (representing the maximal inhibitory effect of insulin), and $\mathbf{E D 5 0}_{\text {INS }}$ is the effective dose of insulin needed to elicit the halfmaximal inhibitory effect of insulin. The results of one normal conditioned cow (BCS 3.0) were excluded from this part of the study because it was not possible to create dose-response curves for the inhibitory effect of insulin.

Statistical Analysis of Parameters Derived from Dose-Response Curves. For the statistical analysis of influences on the parameters of the doseresponse curves, different models were created with the parameters as dependent variables. Parameters $\max _{\text {ISO }}$ and $\min _{\text {INS }}$ were normally distributed and a mixed linear model (PROC MIXED) was used with depot and adipocyte volume as independent variables; cow was included as random factor. Parameters ED50 ISO and ED50 INS were lognormally distributed, and a generalized linear mixed model (PROC GLIMMIX) was used with depot and adipocyte volume as independent variables; cow was included as random factor. Because BCS and volume of the adipocytes were highly correlated ( $\mathrm{r}$ $>0.60$ ), only volume of the adipocytes was included as independent variable in the model.

\section{RESULTS}

\section{Animal and Depot Characteristics}

The BCS of cows in the present study are given in Table 1, whereas other animal characteristics (backfat thickness, peripheral NEFA levels, BW, and depot weight) are presented in De Koster et al. (2015). The volume of the adipocytes was comparable in both adipose depots and ranged from 0.38 to $1.59 \mathrm{~nL}$ in subcutaneous adipose tissue and from 0.23 to $1.62 \mathrm{~nL}$ in omental adipose tissue (Table 1). With increasing BCS, the size of the adipocytes increased linearly, as demonstrated by a positive correlation between volume of the adipocytes and BCS of the animals (Figure 1; r $=0.91$ and 0.94 in subcutaneous and omental adipose tissue, respectively, $P<0.05$ for both). The number of adipocytes per gram of adipose tissue ranged from 0.59 to $2.24 \times 10^{6}$ adipocytes per gram in subcutaneous and from 0.61 to $3.67 \times 10^{6}$ adipocytes per gram in omental adipose tissue (Table 1). Logically, the number of adipocytes per gram of adipose tissue was lower in overconditioned cows than in leaner cows, as demonstrated by the negative correlation between volume of the adipocytes and number of adipocytes per gram of adipose tissue $(\mathrm{r}=-0.93$ and -0.93 in subcutaneous and omental adipose tissue, respectively, $P<0.05$ for both). Regarding the lipid content in both adipose depots, the collected adipose tissue fragments contained, on average, more than $80 \%$ lipid, indicating a low level of contamination of samples by other tissues such as connective tissue and blood vessels (Table 1).

\section{Basal Glycerol Release}

The average basal glycerol release in subcutaneous and omental adipose tissue was 1,325 and 1,038 nmol of glycerol $/ 10^{6}$ adipocytes per $3 \mathrm{~h}$, respectively (Table 2 ). The relationship between the volume of the adipocytes and the basal glycerol release for both depots is depicted in Figure 2. The generalized linear mixed model revealed a positive relationship between the volume of the adipocytes and the basal lipolytic activity but no significant difference could be detected between depots. 
Table 1. Animal and depot characteristics of subcutaneous and omental adipose tissue

\begin{tabular}{lcccc}
\hline Item & Mean & SD & Minimum & Maximum \\
\hline BCS & 3.72 & 0.75 & 2.83 & 5.00 \\
Diameter of the adipocytes $(\mu \mathrm{m})$ & & & & \\
$\quad$ Subcutaneous & 111.5 & 17.7 & 87.3 & 140.9 \\
$\quad$ Omental & 103.1 & 26.5 & 73.5 & 142.8 \\
$\quad$ Volume of the adipocytes $(\mathrm{nL})$ & 0.84 & 0.40 & 0.38 & 1.59 \\
$\quad$ Subcutaneous & 0.73 & 0.53 & 0.23 & 1.62 \\
$\quad$ Omental & & & & \\
Lipid $\%$ fat in adipose tissue) & 83.7 & 3.9 & 77.1 & 87.5 \\
$\quad$ Subcutaneous & 85.3 & 4.5 & 76.3 & 91.0 \\
$\quad$ Omental & & & & \\
$\quad$ No. of adipocytes $\left(\times 10^{6}\right.$ adipocytes/g of adipose tissue) & 1.28 & 0.51 & 0.59 & 2.24 \\
$\quad$ Subcutaneous & 2.01 & 1.20 & 0.61 & 3.67 \\
Omental & & & & \\
\hline
\end{tabular}

\section{Isoproterenol-Stimulated Glycerol Release}

Addition of ISO to the culture medium stimulated glycerol release and increased the maximal glycerol release approximately 8 - and 6 -fold compared with the basal glycerol release in subcutaneous and omental adipose tissue, respectively (Table 2). Dose-response curves were created for both depots for each cow (Figure 3) and the shape of each dose-response curve is determined by
2 parameters: $\max _{\mathrm{ISO}}$, the maximal amount of glycerol released above basal glycerol release, and $\mathrm{ED} 50_{\text {ISO }}$, the effective dose of ISO needed to elicit the half maximal glycerol release (Table 3 ). The parameter $\max _{\text {ISO }}$ was influenced by the size of the adipocytes (volume) and an interaction between both size of the adipocytes and the depot (Table 4, Figure 4); ED50 ISO was negatively influenced by the size of the adipocytes, independent of the adipose depot (Table 4).

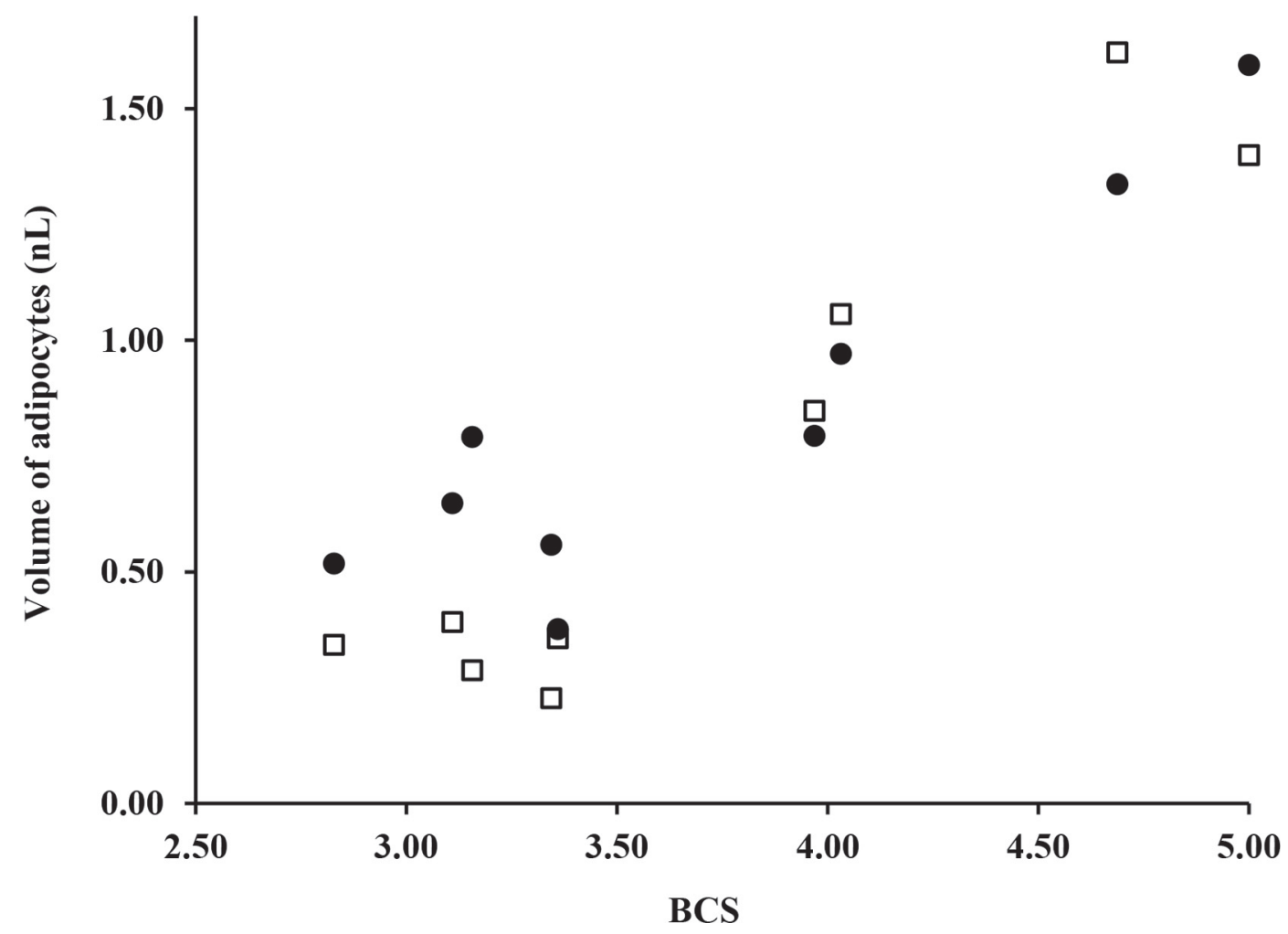

Figure 1. Visualization of the relationship between BCS of the animals and the volume of the adipocytes in subcutaneous $(\square)$ adipose tissue. Points represent the observations of the individual animals. 
Table 2. Glycerol release (mean $\pm \mathrm{SEM}$ ) of subcutaneous and omental adipose tissue in the basal state, after the addition of isoproterenol $\left(10^{-6}, 10^{-7}, 10^{-8}\right.$, or $\left.10^{-9} M\right)$ or insulin $(1,10,200$, or $1,000 \mu \mathrm{IU} / \mathrm{mL})$

\begin{tabular}{lcc}
\hline Item & Subcutaneous & Omental \\
\hline Basal glycerol release $^{1}$ & $1,325 \pm 320$ & $1,038 \pm 258$ \\
Isoproterenol-stimulated glycerol release $^{2}$ & & \\
$10^{-6} M$ & $8,935 \pm 1,027$ & $5,748 \pm 814$ \\
$10^{-7} M$ & $7,992 \pm 990$ & $5,896 \pm 822$ \\
$10^{-8} M$ & $7,588 \pm 1,072$ & $4,423 \pm 746$ \\
$10^{-9} M$ & $3,035 \pm 1,002$ & $1,310 \pm 579$ \\
Insulin-inhibited glycerol release $^{3}$ & & \\
$1 \mu \mathrm{IU} / \mathrm{mL}$ & $84.1 \pm 4.7$ & $90.3 \pm 3.6$ \\
$10 \mu \mathrm{IU} / \mathrm{mL}$ & $68.9 \pm 6.0$ & $81.6 \pm 3.6$ \\
$200 \mu \mathrm{IU} / \mathrm{mL}$ & $68.6 \pm 4.1$ & $78.2 \pm 4.0$ \\
$1000 \mu \mathrm{IU} / \mathrm{mL}$ & $71.4 \pm 4.9$ & $76.7 \pm 5.3$ \\
\hline
\end{tabular}

${ }^{1}$ In nmol of glycerol $/ 10^{6}$ adipocytes per $3 \mathrm{~h}$.

${ }^{2}$ Given as the incremental glycerol release above basal (in nmol of glycerol $/ 10^{6}$ adipocytes per $3 \mathrm{~h}$ ).

${ }^{3}$ Calculated as percentage of the maximal isoproterenol stimulated glycerol release without insulin.

\section{Insulin-Inhibited Glycerol Release}

Addition of insulin inhibited the ISO-stimulated glycerol release in both subcutaneous and omental adipose tissue. At maximal insulin concentration, glycerol release was decreased by 23 to $29 \%$ compared with the maximal ISO-stimulated glycerol release in omental and subcutaneous adipose tissue, respectively (Table 2 ). Dose-response curves were created for both depots for each cow (Figure 5) and the shape of each doseresponse curve is determined by 2 factors: $\min _{\text {INS }}$, the minimal percentage of glycerol released from the explants, and ED50 INS , the effective dose of insulin needed to elicit the half-minimal glycerol release (Table 3). The

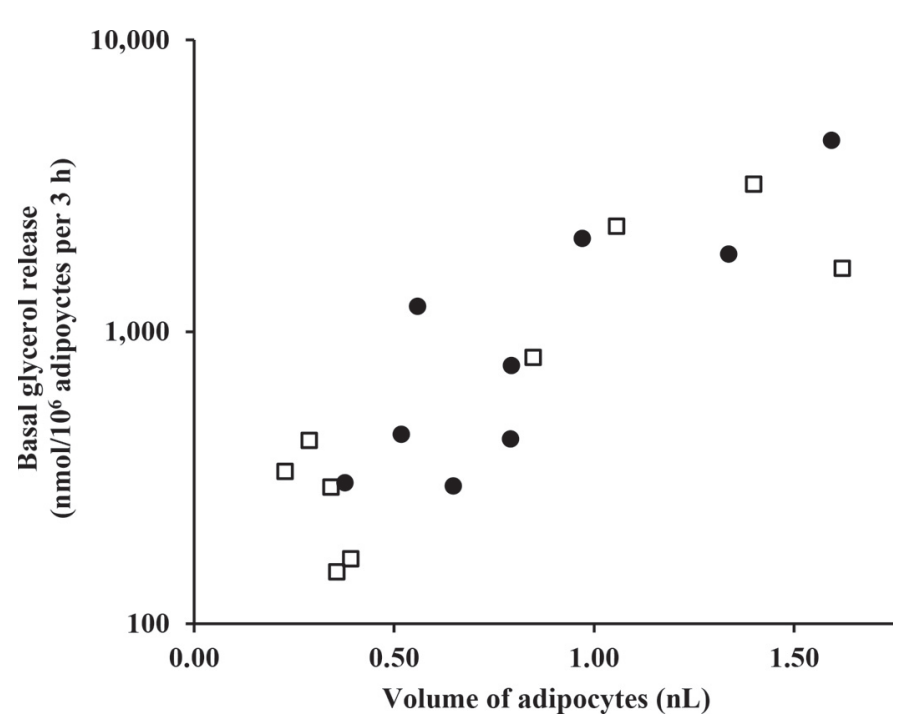

Figure 2. Visualization of the relationship between the volume of the adipocytes and the basal glycerol release in subcutaneous $(\bullet)$ and omental $(\square)$ adipose tissue. Points represent the observations of the individual animals. parameter $\min _{\text {INS }}$ was influenced by the volume of the adipocytes (trend), whereas the adipose depot had no effect (Table 4); ED $50_{\text {INS }}$ was not influenced by either depot or size of the adipocytes (Table 4).

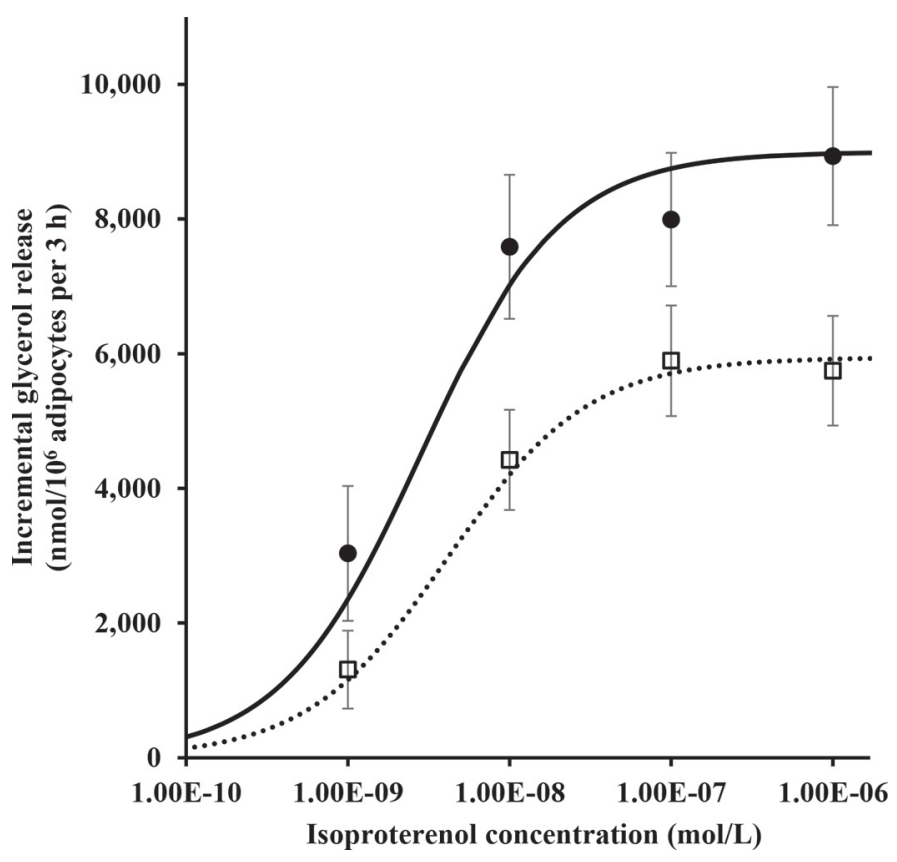

Figure 3. Visualization of the incremental glycerol release of the adipose tissue explants after addition of isoproterenol. Points represent the means of the incremental glycerol release of subcutaneous $(\bullet)$ and omental ( $\square$ ) adipose tissue, and vertical error bars represent the SEM. The lines represent the fitted dose-response curves from the nonlinear equation: Incremental glycerol release $=\frac{\max _{\text {ISO }}}{\left(1+10^{\log E \text { ED50 ISO }-\log I S O}\right)}$ for subcutaneous $(-)$ and omental (...) adipose tissue, with max ISO $_{\text {be- }}$ ing the maximal amount of glycerol released from the explants and ED $50_{\text {ISO }}$ being the effective dose of isoproterenol needed to elicit the half maximal glycerol release. 
Table 3. Model parameters (mean \pm SEM) of the dose-response curves of the stimulated and inhibited glycerol release

\begin{tabular}{|c|c|c|}
\hline Item & Subcutaneous & Omental \\
\hline $\begin{array}{l}\text { Insulin-inhibited glycerol release }{ }^{2} \\
\min _{\text {INS }}(\%) \\
\operatorname{ED} 0_{\text {INS }}(\mu \mathrm{IU} / \mathrm{mL})\end{array}$ & $\begin{array}{l}68.8 \pm 4.5 \\
1.36 \pm 0.51\end{array}$ & $\begin{array}{l}76.8 \pm 5.2 \\
5.05 \pm 2.35\end{array}$ \\
\hline
\end{tabular}

${ }^{1}$ Calculated as the incremental glycerol release above basal. Dose-response curves were created using the PROC NLIN function using the following equation: Incremental glycerol release $=\frac{\max _{\mathrm{ISO}}}{\left(1+10^{\log \mathrm{ED} 50_{\mathrm{ISO}}-\log I S O}\right)}$. The shape of the dose-response curve is determined by 2 parameters: max $_{\mathrm{ISO}}$, being the maximal amount of glycerol released from the explants, and ED50 ${ }_{\text {ISO }}$, being the effective dose of isoproterenol needed to elicit the half-maximal glycerol release.

${ }^{2}$ Calculated as percentage of the maximal isoproterenol-stimulated glycerol release without insulin. Dose-response curves were created using the

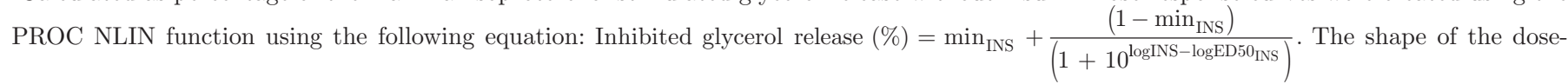
response curve is determined by 2 parameters: $\min _{\text {INS }}$, being the minimal percentage of glycerol released from the explants (representing the maximal inhibitory effect of insulin), and ED $50_{\text {INS }}$, being the effective dose of insulin needed to elicit the half-maximal inhibitory effect of insulin.

\section{DISCUSSION}

In this study, we investigated the influence of adipocyte size and adipose depot location on the lipolytic activity of adipocytes in basal conditions and after addition of different concentrations of catecholamine and insulin in dry dairy cows across a range of BCS. We hypothesized that larger adipocytes from overconditioned cows are more insulin resistant and have higher basal and stimulated lipolytic activity, which potentially contributes to excessive fat mobilization in the periparturient period.

\section{Study Design}

To avoid the effect of feeding level during the dry period on adipose tissue metabolism, the cows in the present study were fed according to their requirements, as reported by De Koster et al. (2015). Explant cultures of adipose tissue were used to reflect, as much as possible, the in vivo activity of the adipocytes and to preserve paracrine interactions between different cell types in the adipose tissue (Fried and Moustaid-Moussa, 2001). Results of the in vitro experiments are reported as glycerol release per million adipocytes rather than per unit of tissue weight to correct for the observed change in cellularity. Overconditioned cows have fewer adipocytes per gram of adipose tissue because larger adipocytes from overconditioned cows occupy more volume compared with smaller adipocytes from lean cows. Because the activity of glycerol kinase is negligible in adipocytes, further metabolism of glycerol is impossible and therefore glycerol release is a good indicator for in vitro lipolytic activity. In contrast, released NEFA

Table 4. Coefficients of the regression models describing the relationship between volume of the adipocytes and adipose depot, and the basal lipolysis and the parameters of the dose-response curves of the isoproterenol (ISO)-stimulated and insulin (INS)-inhibited glycerol release

\begin{tabular}{|c|c|c|c|c|c|}
\hline \multirow[b]{2}{*}{ Item } & \multirow[b]{2}{*}{ Basal lipolysis ${ }^{1}$} & \multicolumn{2}{|c|}{$\begin{array}{l}\text { Isoproterenol-stimulated } \\
\text { glycerol release }\end{array}$} & \multicolumn{2}{|c|}{$\begin{array}{l}\text { Insulin-inhibited glycerol } \\
\text { release }\end{array}$} \\
\hline & & $\max _{\mathrm{ISO}}^{2}$ & ED50 ${ }_{\text {ISO }}{ }^{1}$ & $\min _{\mathrm{INS}}{ }^{2}$ & ED50 ${ }_{\text {INS }}^{1}$ \\
\hline Intercept & $5.39^{*}$ & 1,062 & $-18.10^{*}$ & $55.09^{*}$ & -1.26 \\
\hline Volume & $1.61^{*}$ & $9,414^{*}$ & $-1.88^{*}$ & $16.28 \dagger$ & 1.32 \\
\hline \multicolumn{6}{|l|}{ Adipose depot } \\
\hline Subcutaneous & Referent & Referent & Referent & Referent & Referent \\
\hline Volume $\times$ subcutaneous & & Referent & & & \\
\hline Volume $\times$ omental & & $-3,352^{*}$ & & & \\
\hline
\end{tabular}

${ }^{1}$ Regression coefficients of the generalized linear mixed model; ED50 ISO and ED50 INS $=$ the effective dose of ISO or INS needed to elicit the halfmaximal glycerol release (ISO) or the half-maximal inhibitory effect of insulin (INS).

${ }^{2}$ Regression coefficients of the linear mixed model; $\max _{\mathrm{ISO}}$ and $\min _{\mathrm{INS}}=$ maximal (ISO) or minimal (INS) amount of glycerol released, respectively

${ }^{*} P<0.05 ; \dagger 0.05<P<0.1$. 


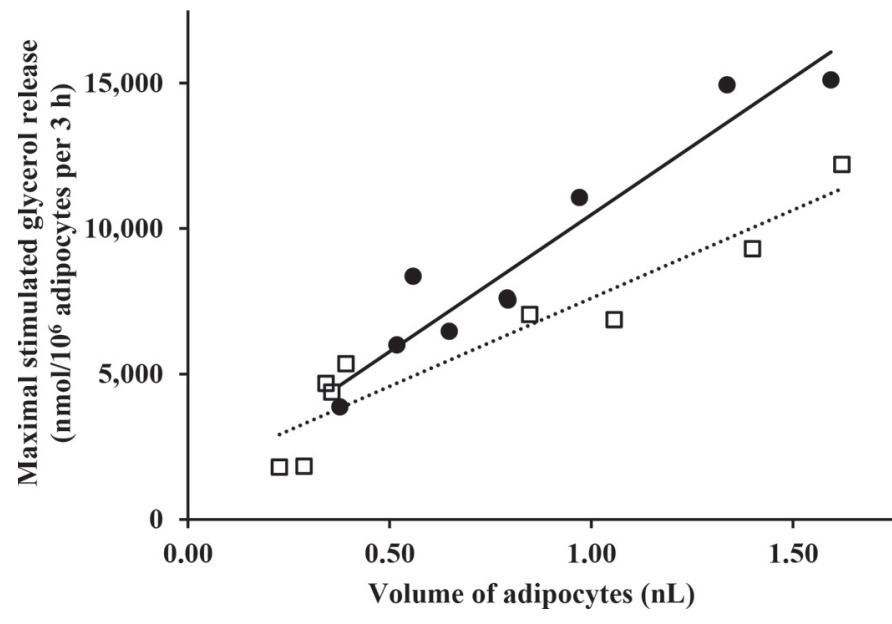

Figure 4. Visualization of the interaction effect of depot and volume of the adipocytes on the maximal isoproterenol-stimulated glycerol release $\left(\max _{\mathrm{ISO}}\right)$. Points represent the observations of subcutaneous $(\bullet)$ and omental $(\square)$ adipose tissue, and lines represent the linear regression for subcutaneous $(-)$ and omental (...) adipose tissue.

can be reutilized in the re-esterification pathway in the adipocytes and therefore NEFA cannot be used as an indicator for in vitro lipolysis (Lafontan, 2012).

\section{Basal Lipolytic Activity}

Similarly to Gagliostro and Chilliard (1991), the basal lipolytic activity of subcutaneous and omental adipose tissue in the present study increased with adipocyte volume, meaning that larger fat cells have higher basal lipolytic activity. Pike and Roberts (1984) failed to detect any relationship between adipocyte size and lipolytic activity, probably due to the low variability in adipocyte size in their study. Because adipose triglyceride lipase is the main regulator of basal lipolytic activity (Elkins and Spurlock, 2009; Koltes and Spurlock, 2011), we speculate that the activity of this enzyme is upregulated in larger adipocytes. The combination of the greater absolute fat mass and the higher basal lipolytic activity of large adipocytes indicates that overconditioned cows are continuously exposed to elevated levels of NEFA already before calving. An increased concentration of NEFA in the prepartum period is an important risk factor for the development of fatty liver, ketosis, and associated diseases (Ospina et al., 2013).

\section{Isoproterenol-Stimulated Lipolytic Activity}

Isoproterenol is a nonselective $\beta$-agonist and used as a potent stimulator of lipolysis in adipocytes (Lafontan et al., 1997). Maximal effect of lipolytic agents is expected at concentrations between 1 and $10 \mu M$ (Carpéné, 2001). In the present study, a logarithmic dilution

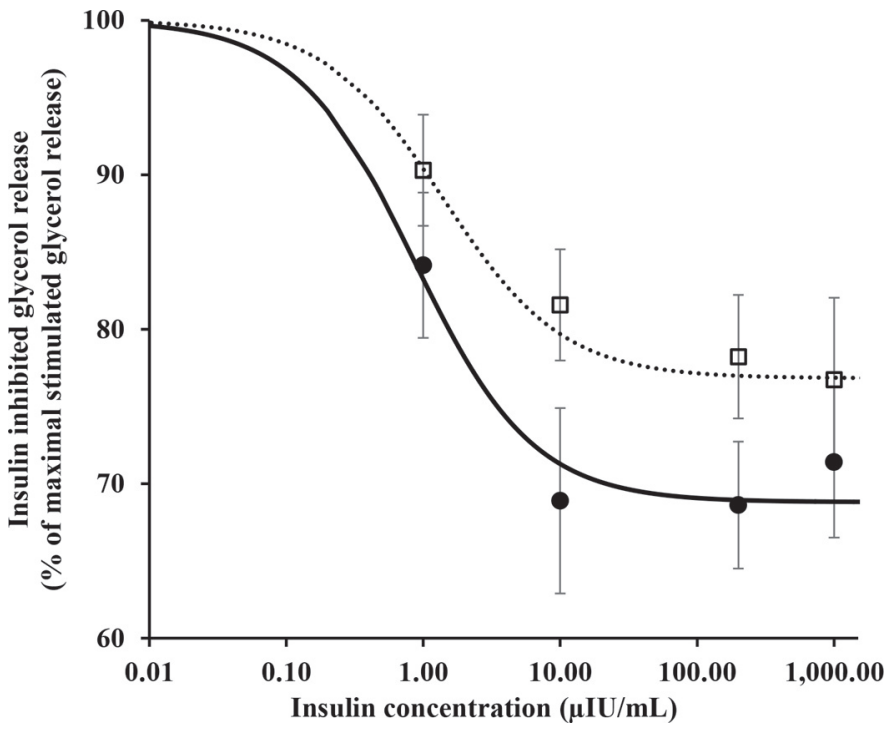

Figure 5. Visualization of the inhibition of the glycerol release of the adipose tissue explants after addition of insulin. Points represent the percentage of the maximal isoproterenol stimulated glycerol release of subcutaneous $(\bullet)$ and omental $(\square)$ adipose tissue, and vertical error bars represent the SEM. The lines represent the fitted dose-response curves from the nonlinear equation: Insulin-inhibited glycerol release $(\%)=\min _{\mathrm{INS}}+\frac{\left(1-\min _{\mathrm{INS}}\right)}{\left(1+10^{\left.\log I N S-\operatorname{logED} 50_{\mathrm{INS}}\right)}\right.}$ for subcutaneous (-) and omental (..) adipose tissue, with $\min _{\text {INS }}$ being the minimal percentage of glycerol released from the explants, and $\mathrm{ED} 50_{\text {INS }}$ being the effective dose of insulin needed to elicit the half-maximal inhibitory effect of insulin on the lipolytic activity.

series of ISO was used to characterize the dose-response curve of adipose tissue. Based on these dose-response curves, we conclude that in dairy cows at the end of the dry period, larger fat cells have a higher sensitivity toward lipolytic signals, as demonstrated by a negative influence of size of the adipocytes on ED50 $0_{\text {ISO }}$. This means that, compared with smaller adipocytes, large adipocytes will release more NEFA and glycerol when exposed to a certain amount of ISO. Additionally, the larger fat cells released more glycerol upon maximal stimulation with ISO and the effect of increase in adipocyte volume on $\max _{\text {ISO }}$ was more pronounced in subcutaneous adipose tissue. As a consequence, during lipolytic conditions, overconditioned cows (which have large adipocytes) will mobilize more fat and will mobilize fat preferentially from the subcutaneous depots, whereas cows in normal BCS (small adipocytes) will mobilize fat equally from subcutaneous and omental adipose tissue. This might explain the fact that in some cows surgically corrected for a left displacement of the abomasum (LDA), substantial amounts of fat can be found in the omentum while a relatively low BCS (reflecting subcutaneous adipose tissue) is found (Hostens et al., 2012). Fat cows are more susceptible for LDA 
(Shaver, 1997) and at the moment of surgical correction for LDA (typically 2 to 3 wk after calving), the subcutaneous adipose depot of these cows might already be depleted of triglycerides due to extensive mobilization in the immediate postpartum period. In the same study, Hostens et al. (2012) found that the fatty acid profile of circulating NEFA was more comparable to that of the omental adipose tissue, suggesting that at the moment of surgical correction for LDA, circulating NEFA mainly originate from the abdominal adipose depots. The authors suggested that this might be due to increased blood flow in the abdominal fat depots and differences in metabolic activity between the adipose depots. In addition to both suggestions, we hypothesize that due to the greater mass of the abdominal adipose depot ( $66.7 \%$ of total body fat) compared with the subcutaneous adipose depot (17.9\% of total body fat; De Koster et al., 2015), the former is expected to be a more important contributor to the circulating NEFA.

The immediate postpartum period is characterized by an increase in lipolytic sensitivity and stimuli and a concomitant decrease in antilipolytic sensitivity and stimuli (Bauman and Currie, 1980; McNamara, 1991). During the lipolytic conditions of the immediate postpartum period, large adipocytes will release more NEFA compared with smaller adipocytes. Therefore, overconditioned cows will mobilize enormous amounts of fat, leading to an overflow of NEFA in the liver with associated adverse health effects such as ketosis and fatty liver (Drackley, 1999).

\section{Insulin-Inhibited Lipolytic Activity}

Insulin inhibits only catecholamine-stimulated lipolytic activity and has no effect on basal lipolytic activity (Morimoto et al., 1998). Therefore in the present study, inhibitory activity of insulin was tested after stimulation of the lipolytic activity of adipocytes with $10^{-6} M$ ISO. A dilution series of insulin was used to characterize the dose-response curve of adipose tissue by nonlinear regression to obtain the maximal inhibitory effect ( $\left.\min _{\text {INS }}\right)$ and the insulin concentration needed to elicit half-maximal effect (ED50 INS $)$. Insulin inhibited the ISO-stimulated lipolytic activity in a dose-dependent manner. We observed a trend for larger adipocytes to be more resistant to the maximal inhibitory effect of insulin. The insulin sensitivity or ED50 INS was within the physiological range of insulin and was not influenced by adipocyte size. In vivo results in the same cows demonstrate no effect of overconditioning on insulin response of fatty acid metabolism, whereas the insulin response of glucose metabolism was clearly attenuated in overconditioned dry cows (De Koster et al., 2015). Differences between in vivo and in vitro results might be explained by the fact that in vivo results are measured at the total body level, whereas in vitro results are measured at adipose depot level. In vitro, only lipolytic activity is taken into account, whereas in vivo, more metabolic pathways such as $\beta$-oxidation, re-esterification, and lipogenesis play a role in the circulating concentration of NEFA (Roche et al., 2013). Despite the general acceptance that the lipolytic pathway is insulin resistant in overconditioned cows, as proposed by Herdt (2000), results of the present study do not support this assumption. We observed a trend for decreased maximal inhibitory effect of insulin on lipolysis in large adipocytes at concentrations well above the normal physiological range, whereas the half-maximal effect of insulin was reached at normal physiological concentrations and was not influenced by fatness of the animals, meaning that the antilipolytic effect of insulin in physiological conditions remains intact across a range of $\mathrm{BCS}$. Although $\mathrm{min}_{\text {ins }}$ and $\mathrm{ED} 50_{\text {ins }}$ differed numerically between the subcutaneous and omental adipose depot, differences were not statistically significant, probably because of the small number of cows in the study. The present research indicates some variability in metabolism between adipose depots; therefore, further research is warranted to distinguish metabolic properties of the different adipose depots in dairy cows.

\section{CONCLUSIONS}

Overconditioned dairy cows are destined to excessive mobilization of NEFA and associated adverse health conditions in the periparturient period due to several factors. In the present study, we investigated the role of the adipose tissue in this increased disease susceptibility of overconditioned cows at the end of the dry period. We conclude that in overconditioned cows, the absolute amount of fat is greatly increased and therefore, more fat is available to mobilize during lipolytic conditions. Additionally, the adipocytes in the adipose depots of overconditioned cows are enlarged and the metabolic properties of these large adipocytes are characterized by an increased basal and catecholamine-stimulated lipolytic activity. Contrary to general acceptance, we found no clear evidence for a state of insulin resistance of the antilipolytic effect of insulin in large adipocytes. Differences between the subcutaneous and omental adipose depots were limited to the fact that during lipolytic conditions, overconditioned cows will mobilize fat preferentially from the subcutaneous depots, whereas cows in normal BCS will mobilize fat equally from the subcutaneous and omental adipose tissue. However, more research is needed to identify the metabolic properties of the different adipose depots of dairy cows. 


\section{DE KOSTER ET AL.}

\section{ACKNOWLEDGMENTS}

This research was funded by the Special Research Fund of Ghent University (Merelbeke, Belgium; grant number 01D28410). The authors thank Isabel Lemahieu and Petra Van Damme (Ghent University, Merelbeke, Belgium) for excellent technical assistance in the laboratory.

\section{REFERENCES}

Bauman, D. E., and W. B. Currie. 1980. Partitioning of nutrients during pregnancy and lactation-A review of mechanisms involving homeostasis and homeorhesis. J. Dairy Sci. 63:1514-1529.

Carpéné, C. 2001. Assays of adrenergic receptors. Including lipolysis and binding measurements. Methods Mol. Biol. 155:129-140.

De Koster, J., M. Hostens, M. Van Eetvelde, K. Hermans, S. Moerman, H. Bogaert, E. Depreester, W. Van den Broeck, and G. Opsomer. 2015. Insulin response of the glucose and fatty acid metabolism in dry dairy cows across a range of body condition scores. J. Dairy Sci. 98:4580-4592.

Di Girolamo, M., and J. B. Fine. 2001. Cellularity measurements. Methods Mol. Biol. 155:65-75.

Di Girolamo, M., S. Mendlinger, and J. W. Fertig. 1971. Simple method to determine fat cell size and number in four mammalian species. Am. J. Physiol. 221:850-858.

Drackley, J. K. 1999. Biology of dairy cows during the transition period: The final frontier? J. Dairy Sci. 82:2259-2273.

Drackley, J. K., R. L. Wallace, D. Graugnard, J. Vasquez, B. F. Richards, and J. J. Loor. 2014. Visceral adipose tissue mass in nonlactating dairy cows fed diets differing in energy density. J. Dairy Sci. 97:3420-3430.

Edmonson, A. J., I. J. Lean, L. D. Weaver, T. Farver, and G. Webster. 1989. A body condition scoring chart for Holstein dairy cows. J. Dairy Sci. 72:68-78.

Elkins, D. A., and D. M. Spurlock. 2009. Phosphorylation of perilipin is associated with indicators of lipolysis in Holstein cows. Horm. Metab. Res. 41:736-740.

Fried, S. K., and N. Moustaid-Moussa. 2001. Culture of adipose tissue and isolated adipocytes. Methods Mol. Biol. 155:197-212.

Gagliostro, G., and Y. Chilliard. 1991. Duodenal rapeseed oil infusion in early and midlactation cows. 4 . In vivo and in vitro adipose tissue lipolytic responses. J. Dairy Sci. 74:1830-1843.

Goldrick, R. B. 1967. Morphological changes in the adipocyte during fat deposition and mobilization. Am. J. Physiol. 212:777-782.

Grummer, R. R., D. G. Mashek, and A. Hayirli. 2004. Dry matter intake and energy balance in the transition period. Vet. Clin. North Am. Food Anim. Pract. 20:447-470.

Herdt, T. H. 2000. Ruminant adaptation to negative energy balance. Influences on the etiology of ketosis and fatty liver. Vet. Clin. North Am. Food Anim. Pract. 16:215-230.

Hostens, M., V. Fievez, J. L. Leroy, J. Van Ranst, B. Vlaeminck, and G. Opsomer. 2012. The fatty acid profile of subcutaneous and abdominal fat in dairy cows with left displacement of the abomasum. J. Dairy Sci. 95:3756-3765.

Kokkonen, T., J. Taponen, T. Anttila, L. Syrjala-Qvist, C. Delavaud, Y. Chilliard, M. Tuori, and A. T. Tesfa. 2005. Effect of body fatness and glucogenic supplement on lipid and protein mobilization and plasma leptin in dairy cows. J. Dairy Sci. 88:1127-1141.
Koltes, D. A., and D. M. Spurlock. 2011. Coordination of lipid dropletassociated proteins during the transition period of Holstein dairy cows. J. Dairy Sci. 94:1839-1848.

Lafontan, M. 2012. Historical perspectives in fat cell biology: The fat cell as a model for the investigation of hormonal and metabolic pathways. Am. J. Physiol. Cell Physiol. 302:C327-C359.

Lafontan, M., P. Barbe, J. Galitzky, G. Tavernier, D. Langin, C. Carpene, A. Bousquet-Mélou, and M. Berlan. 1997. Adrenergic regulation of adipocyte metabolism. Hum. Reprod. 12(Suppl. $1): 6-20$.

Locher, L. F., N. Meyer, E. M. Weber, J. Rehage, U. Meyer, S. Danicke, and K. Huber. 2011. Hormone-sensitive lipase protein expression and extent of phosphorylation in subcutaneous and retroperitoneal adipose tissues in the periparturient dairy cow. J. Dairy Sci. 94:4514-4523.

Locher, L. F., J. Rehage, N. Khraim, U. Meyer, S. Danicke, K. Hansen, and K. Huber. 2012. Lipolysis in early lactation is associated with an increase in phosphorylation of adenosine monophosphateactivated protein kinase (AMPK) alpha 1 in adipose tissue of dairy cows. J. Dairy Sci. 95:2497-2504.

Lourenço, M., G. Van Ranst, S. De Smet, K. Raes, and V. Fievez. 2007. Effect of grazing pastures with different botanical composition by lambs on rumen fatty acid metabolism and fatty acid pattern of longissimus muscle and subcutaneous fat. Animal 1:537-545.

McNamara, J. P. 1991. Regulation of adipose tissue metabolism in support of lactation. J. Dairy Sci. 74:706-719.

Morimoto, C., T. Tsujita, and H. Okuda. 1998. Antilipolytic actions of insulin on basal and hormone-induced lipolysis in rat adipocytes. J. Lipid Res. 39:957-962.

Motulsky, H., and A. Christopoulos. 2004. Fitting models to biological data using linear and nonlinear regression: A practical guide to curve fitting. Oxford University Press, San Diego CA.

Ospina, P. A., J. McArt, T. Overton, T. Stokol, and D. Nydam. 2013. Using nonesterified fatty acids and $\beta$-hydroxybutyrate concentrations during the transition period for herd-level monitoring of increased risk of disease and decreased reproductive and milking performance. Vet. Clin. North Am. Food Anim. Pract. 29:387-412.

Pike, B. V., and C. J. Roberts. 1984. Size and lipolytic capacity of bovine adipocytes from subcutaneous and internal adipose tissue. Vet. Res. Commun. 8:61-64.

Pond, C. M. 1992. An evolutionary and functional view of mammalian adipose-tissue. Proc. Nutr. Soc. 51:367-377.

Roche, J. R., J. K. Kay, N. C. Friggens, J. J. Loor, and D. P. Berry. 2013. Assessing and managing body condition score for the prevention of metabolic disease in dairy cows. Vet. Clin. North Am. Food Anim. Pract. 29:323-336.

Rukkwamsuk, T., T. Wensing, and M. J. H. Geelen. 1998. Effect of overfeeding during the dry period on regulation of adipose tissue metabolism in dairy cows during the periparturient period. J. Dairy Sci. 81:2904-2911.

Shaver, R. D. 1997. Nutritional risk factors in the etiology of left displaced abomasum in dairy cows: A review. J. Dairy Sci. 80:24492453.

Vernon, R. G. 2005. Lipid metabolism during lactation: A review of adipose tissue-liver interactions and the development of fatty liver. J. Dairy Res. 72:460-469.

Vernon, R. G., R. G. P. Denis, and A. Sorensen. 2001. Signals of adiposity. Domest. Anim. Endocrinol. 21:197-214.

Viswanadha, S., and C. Londos. 2008. Determination of lipolysis in isolated primary adipocytes. Methods Mol. Biol. 456:299-306.

Wajchenberg, B. L. 2000. Subcutaneous and visceral adipose tissue: Their relation to the metabolic syndrome. Endocr. Rev. 21:697738 . 